\title{
Histamine Blood Concentration in Ischemic Heart Disease Patients
}

\author{
Vladimir Zdravkovic, ${ }^{1,2}$ Suzana Pantovic, ${ }^{1}$ Gvozden Rosic, ${ }^{1}$ Aleksandra Tomic-Lucic, ${ }^{1,2}$ \\ Nemanja Zdravkovic, ${ }^{1}$ Maja Colic, ${ }^{1}$ Zdravko Obradovic, ${ }^{1}$ and Mirko Rosic ${ }^{1,3}$ \\ ${ }^{1}$ Department of Physiology, Faculty of Medicine, University of Kragujevac, 69 Svetozara Markovica Street, 34000 Kragujevac, Serbia \\ ${ }^{2}$ Division of Internal Medicine, Medical Centre of Kragujevac, 30 Zmaj Jovina Street, 34000 Kragujevac, Serbia \\ ${ }^{3}$ Research Center of Serbian Academy of Arts and Sciences and University of Kragujevac, Jovana Cvijica Street bb, \\ 34000 Kragujevac, Serbia \\ Correspondence should be addressed to Mirko Rosic, mrosic@medf.kg.ac.rs
}

Received 27 December 2010; Revised 18 March 2011; Accepted 14 April 2011

Academic Editor: Saulius Butenas

Copyright ( $) 2011$ Vladimir Zdravkovic et al. This is an open access article distributed under the Creative Commons Attribution License, which permits unrestricted use, distribution, and reproduction in any medium, provided the original work is properly cited.

\begin{abstract}
The aim of this study was to investigate histamine blood concentration in subjects suffering from different types of ischemic heart diseases during the period of eight days. Our results showed that the histamine blood level was associated with different types of ischemic heart diseases. The blood histamine level in all investigated patients was significantly higher when compared to control subjects $\left(44.87 \pm 1.09 \mathrm{ng} \mathrm{mL}^{-1}\right)$, indicating the increase of histamine release in patients suffering from coronary diseases. In patients suffering from ACS-UA and ACS-STEMI, the second day peak of histamine level occurs $\left(90.85 \pm 6.34 \mathrm{ng} \mathrm{mL}^{-1}\right.$ and $121.7 \pm 6.34 \mathrm{ng} \mathrm{mL}^{-1}$, resp.) probably as the reperfusion event. Furthermore, our data suggest that histamine can be additional parameter of myocardial ischemia along with cardiac specific enzymes and may prove to be an excellent single prognostic marker for multitude of ischemic heart diseases.
\end{abstract}

\section{Introduction}

Histamine, a low-molecular-weight amine synthesized from L-histidine in the reaction catalyzed by L-histidine decarboxylase, is known to activate the four $\mathrm{G}$ protein-coupled receptors: $\mathrm{H} 1, \mathrm{H} 2, \mathrm{H} 3$ and $\mathrm{H} 4$, through which it is involved in the regulation of several physiological processes [1]. Although it is contained in almost all tissues in human organism, it is most frequently found in mast cells and basophilic leukocytes. This biogenic amine is released by endothelial cells, aggregating platelets, lymphocytes, and monocytes/macrophages [2, 3]. Mast cells and histamine also have cranium-caudal distribution in the heart which means that the largest quantity of this amine is in the right atrium and the least in left ventricle tissue. Increased number of mast cells was found in coronary blood vessels adventitia in the patients suffering from ischemic heart diseases, especially in the narrow parts of blood vessels, or at the site of plaque rupture $[4,5]$. Obvious connection was also determined between coronary blood vessel inflammation and mast cells activation in the process of atherogenesis [6, 7]. Furthermore, previous studies have shown that histamine affects atherosclerosis through $\mathrm{H} 1$ receptor mechanisms [8]. For example, histamine enhances the expression of adhesion molecules in vascular endothelial cells, thereby augmenting leukocyteendothelial cell interactions, an important onset event in atherogenesis [8]. Moreover, this biogenic amine suppresses hepatic LDL receptor expression and reduces plasma HDL cholesterol in rats [9]. This suggests that histamine may play an important role in lipoprotein metabolism, which may be related to its role in the development of atherosclerosis. Histamine has also been shown to increase smooth muscle cell proliferation and migration and implicated in intimal thickening and atherogenesis [6].

Histamine's effects on coronary arteries are the result of multiple actions of this molecule on both smooth muscle and endothelial cells. Relaxation and constriction of coronary vessels have been widely reported as its effects. These effects 
are species specific and depend on dose of histamine, diameter and initial vessel tone, and relative location within the coronary circulation [10]. When atherosclerotic coronary artery is concerned histamine is a vasoconstrictor [11]. On the other hand histamine is a proven endotheliumdependent vasodilator which bound with $\mathrm{H} 1$ receptor of endothelial cells activates endothelial nitric oxide synthase [12-14]. Although this eNOS upregulation may be protective under normal circumstances, as it increases NO production, it may become harmful under conditions of oxidative stress when eNOS produces reactive oxygen species (ROS) at the expense of NO [15-18]. Also, it is shown that histamine produces coronary dilation via $\mathrm{H} 2$ receptor, which is not endothelium dependent $[11,12]$, as well as through $\mathrm{H} 2$ - and $\mathrm{H} 3$-dependent mechanism involving the generation of nitric oxide [19].

As said above, histamine is also released from the aggregating platelets, and these observations suggested a possible role of this amine in the pathogenesis of acute coronary syndrome (ACS) [20]. Furthermore, histamine via $\mathrm{H} 1$ receptors induces expression of tissue factor (TF), a key enzyme in the activation of coagulation [5]. The elevated levels of quantity and activity of TF antigen have been detected in plasma and atherectomy specimens of patients with unstable angina and acute myocardial infarction $[5,6]$.

Recent research clearly indicates a great role of histamine in inflammation processes through its influence on cyclooxygenases and increased production of $\mathrm{PGI}_{2}$ and $\mathrm{PGE}_{2}$ [6]. Considering the fact that inflammation is the key factor for atherosclerosis, finally, it is essential to point out the fact that blood histamine alone may be a good prognostic indicator for ischemic event (ACS), better than CRP, even when it is combined with lipid indexes [21].

Up to now research showed that the patients suffering from ischemic heart diseases (stable coronary artery disease (SCAD) and acute coronary syndrome (ACS)) have statistically significantly higher total blood histamine than the population without these diseases [21]. However, these data about histamine blood levels in ACS patients have been obtained only within the first 24 hours of acute event, which is why the aim of this study was to examine histamine blood concentration in subjects suffering from ischemic heart diseases during the period of eight days. Furthermore, we intended to analyze whether histamine blood concentrations in patients depend on different types of ischemic heart diseases such as stable coronary artery disease, acute coronary syndrome, nonocclusive type, or acute coronary syndrome, occlusive type.

\section{Materials and Methods}

All researches were performed according to the ethical standards of the local Ethics Committee and Helsinki Declaration.

2.1. Subjects. Four groups of subjects were observed. Group I: control group included age, sex, and risk factors matched volunteers without coronary disease. All volunteers underwent an initial clinical assessment that included a clinical history taking, a physical examination, electrocardiography, standard blood measurements, and stress echocardiography. Furthermore, none of the volunteers had shown any allergy manifestations $(n=32)$. Group II: subjects suffering from stable coronary artery disease (SCAD patients) determined by symptoms during physical activity, stress echocardiography, coronarography, and so forth $(n=28)$. SCAD is an abbreviation for stable angina. Patients suffering from this disease manifest symptoms (like chest pain, fatigue, etc.) and changes in ECG (such as negative T-wave or ST depression) under exertion while the values of troponin I and CKMB remain normal. Group III: subjects with acute coronary syndrome, nonocclusive type (unstable angina or ACS-UA patients) determined by symptoms during resting period, acute electrocardiographic changes, and coronarography $(n=26)$. Apart from chest pain these subjects also have changes in ECG (such as negative T-wave or the positivity of previously negative $\mathrm{T}$-wave), while the values of troponin I and CKMB are within physiological range. Group IV: subjects with acute coronary syndrome, occlusive type (ACS-STEMI patients) determined by typical accelerating symptoms, acute electrocardiographic changes and levels of serum enzymes (troponin I, CKMB), and coronarography ( $n=37)$. ACS-STEMI is abbreviation for transmural myocardial infarction. Patients suffering from this form of acute coronary syndrome in addition to prolonged chest pain also have changes in ECG (such as elevation of ST segment), and the values of troponin I and CKMB are increased.

Patients in groups II, III, and IV were hospitalized in the Medical Centre (Kragujevac, Serbia). First blood samples were collected within either (1) the first $24 \mathrm{~h}$ of their acute events (ACS-UA and ACS-STEMI patients) after initial medical stabilization or (2) the first $24 \mathrm{~h}$ of their hospitalization in Medical Center of Kragujevac (SCAD patients). The remaining blood samples were collected daily for the following 7 days. The measurement of whole blood histamine was performed as described below. Data points included sex, age, illness, work activities, pain, history of exercise, smoking habits, and other observations (such as anger or nervousness, etc.), as well.

2.2. Biochemical Procedures. The estimation of whole blood histamine was performed immediately after the collection from the study subjects using modified Shore's method for the fluorometric assay of histamine in the tissue [22]. This method is precise, sensitive, and specific for histamine and involves extraction of histamine into $n$-butanol (Polskie Odczynniki Chemiczne S.A., Poland) from alkalinized perchloric acid (Mallinckrodt Baker B.V., Holland) blood sample, return of the histamine to an aqueous solution and condensation with o-phthalaldehyde (OPT) (SIGMA, Germany) to yield a product with strong and stable fluorescence, which is measured in a spectrofluorometer (Perkin-Elmer LS-5B).

2.3. Statistical Analysis. All results are presented as means \pm S.E.M. (standard error of the mean) and analyzed after 
TABLE 1: Clinical characteristics of investigated groups.

\begin{tabular}{lcccc}
\hline & Control & SCAD & ACS-UA & ACS-STEMI \\
\hline Age (years)* & $54 \pm 20$ & $56 \pm 18$ & $56 \pm 20$ & $58 \pm 18$ \\
Male sex (\%) & 56 & 58 & 60 & 60 \\
Hypertension (\%) & 20 & 78 & 77 & 74 \\
Diabetes mellitus (\%) & 10 & 42 & 23 & 21 \\
Smoking (\%) & 62 & 63 & 65 & 59 \\
Heredity (\%) & 31 & 47 & 55 & 58 \\
Lipids in blood (\%) & 30 & 84 & 77 & 82 \\
\hline
\end{tabular}

* Age values in all investigated groups are represented as mean \pm S.E.M.

determination of normality of distribution with Student's $t$ test and ANOVA test, where $P$ value of $<.05$ was considered statistically significant.

\section{Results}

This study examined, as described in Section 2, patients with stable coronary artery disease (SCAD), acute coronary syndrome, nonocclusive type (ACS-UA), and acute coronary syndrome, occlusive type (ACS-STEMI), as well as control group. Clinical characteristics of analyzed groups are shown in Table 1.

The analyzed groups were uniform in terms of age, sex, smoking habits, or physical activity. Hypertension, heredity, and diabetes mellitus type II, as well as total cholesterol, low-density lipoproteins (LDLs), and triglycerides were more frequent in patients with ischemic heart disease than in those of control group (see Table 1).

In terms of medication usage the groups differed as could be expected. Beta-blockers use was the highest in SCAD patients $(80 \%)$ and the least in the control group (10\%) while it ranged from $60 \%$ in ACS-UA patients to $25 \%$ in ACS-STEMI patients. The usage of calcium channel blockers was the highest in SCAD and ACS-UA patients (40\%), intermediate in ACS-STEMI patients (25\%), and the least in control group (5\%). ACE inhibitor usage was similar in all patients (about 50\%), but much lower in control group $(10 \%)$. The usage of nitrates was almost equal in all patients (about $80 \%$ ) versus none in control. Antiplatelets drugs, such as clopidogrel, were taken by ACS patients (UA and STEMI). Fibrinolytics were used only by ACS-STEMI patients. All the patients in heart disease groups were taking acetylsalicylic acid in comparison to $40 \%$ of the control group. It is important to underline the fact that there were no statistically significant differences in histamine blood concentrations among patients in the same group with different therapy $(P>.05)$.

Histamine blood concentrations in the control group, as well as in patients with coronary diseases (SCAD, ACS-UA and ACS-STEMI), during the eight-day period are presented in Figure 1. Histamine blood concentrations in patients with different types of coronary diseases (SCAD, ACS-UA and ACS-STEMI) remained increased in comparison with the control group during the whole testing period. Whole blood

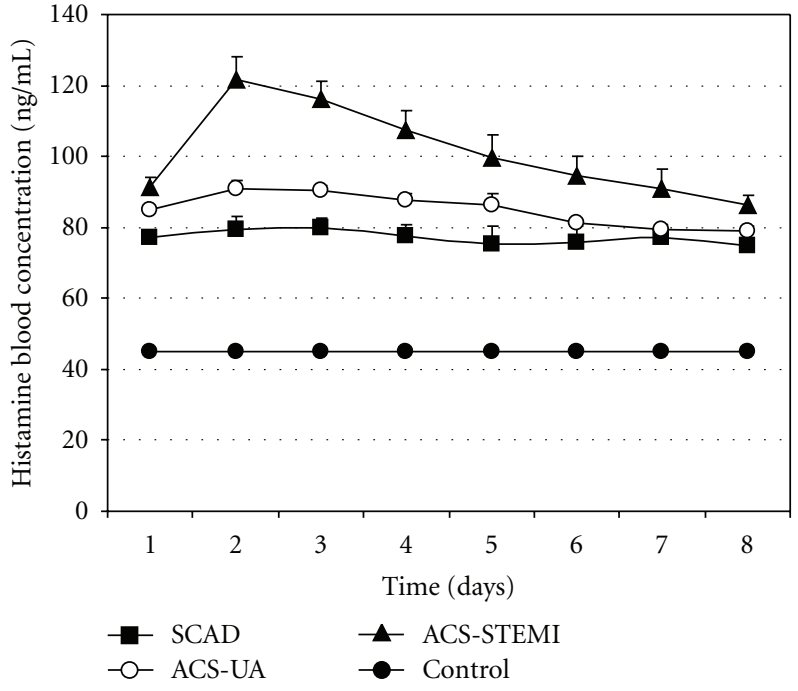

Figure 1: Histamine blood concentration $\left(\mathrm{ng} \mathrm{mL}^{-1}\right)$ in control group $(n=32)$, as well as in the patients with coronary diseases: stable coronary artery disease (SCAD, $n=28$ ), acute coronary syndrome, nonocclusive type (ACS-UA, $n=26$ ), and acute coronary syndrome, occlusive type (ACS-STEMI, $n=37$ ), during the testing period of eight days. The data are presented by means \pm SEM.

histamine concentration in the control group was $44.87 \pm$ $1.09 \mathrm{ng} \mathrm{mL}^{-1}$.

The highest increase of histamine was in ACS-STEMI patients, who had 2- to 3-fold more of this biogenic amine in blood than those in control group (Figure 1). Furthermore, histamine blood concentration in ACS-STEMI patients achieved one peak value on the second day of their acute events $\left(127 \pm 6.34 \mathrm{ng} \mathrm{mL}^{-1}\right)$, after which point histamine blood level steadily decreased throughout the testing period remaining significantly higher when compared with the corresponding histamine blood levels in the other analyzed groups.

Intermediate increase of histamine blood concentration was recorded in ACS-UA patients, where values remained significantly lower than histamine blood concentrations in ACS-STEMI patients during the entire testing period. The highest increase of histamine blood concentrations in ACS-UA patients occurred on the second day (90.85 $\left.\pm 6.34 \mathrm{ng} \mathrm{mL}^{-1}\right)$, the same as in ACS-STEMI patients (Figure 1). During the first five days of histamine blood analysis concentrations in ACS-UA patients were significantly higher than in SCAD patients, whereas there were no significant differences in this respect between these two groups in the last three days.

When SCAD patients are concerned, the histamine blood concentration was significantly increased in comparison with the control group on one hand and significantly lower than that in ACS-STEMI patients on the other hand throughout the testing. During the eight-day observation, concentrations of histamine in patients with stable angina did not vary considerably on daily basis. The lowest value of 


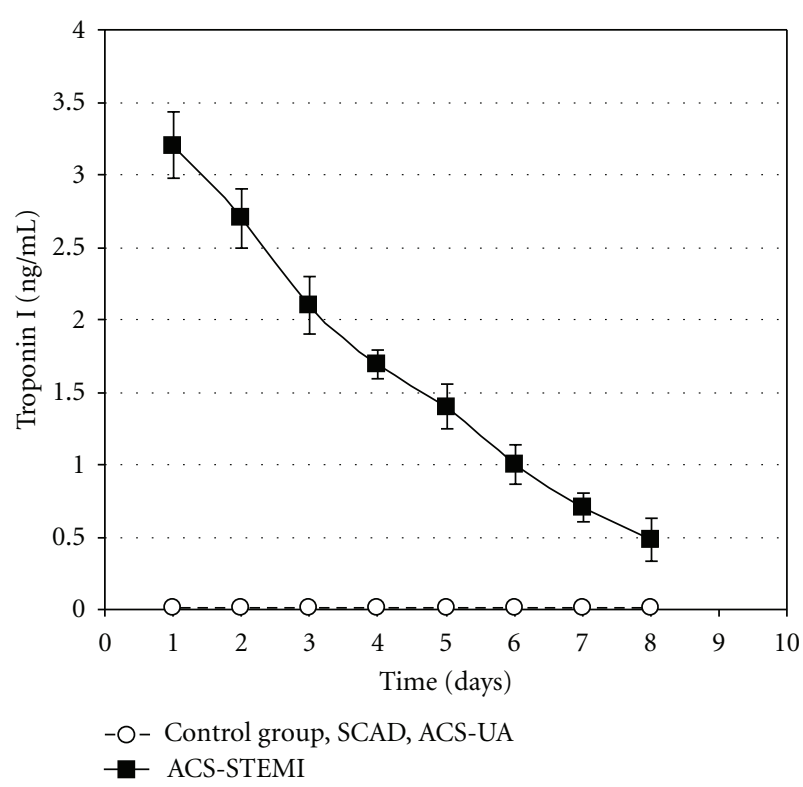

Figure 2: Troponin I blood concentration $\left(\mathrm{ng} \mathrm{mL}^{-1}\right)$ in control group $(n=32)$, stable coronary artery disease patients (SCAD, $n=28$ ), acute coronary syndrome, nonocclusive type, patients (ACS-UA, $n=26$ ), and acute coronary syndrome, occlusive type, patients (ACS-STEMI, $n=37$ ) during the eight-day period of testing. Troponin I blood concentrations in control, SCAD, and ACS-UA groups were in normal physiological range during the whole investigated period (less than $0.01 \mathrm{ng} \mathrm{mL}^{-1}$ ). The data are presented by means \pm SEM.

$74.8 \pm 4.1 \mathrm{ng} \mathrm{mL}{ }^{-1}$ was measured on the last day, while the highest, measured on the third day, was $79.7 \pm 3.1 \mathrm{ng} \mathrm{mL}^{-1}$.

Troponin I blood concentration $\left(\mathrm{ng} \mathrm{mL}^{-1}\right)$ in STEMI, ACS-UA, and ACS-STEMI patients and subjects of control group during the eight-day period is shown in Figure 2. Troponin I blood values were within normal physiological range (less than $0.01 \mathrm{ng} \mathrm{mL}^{-1}$ ) during the whole testing period in control, SCAD, and ACS-UA groups. On the other hand, troponin I blood concentrations in ACS-STEMI patients were significantly increased. Troponin I blood level in ACS-STEMI patients achieved peak value in the first 24 hours, which is much higher $\left(3.2 \pm 0.23 \mathrm{ng} \mathrm{mL}^{-1}\right)$ than physiological ranges for this cardiac specific enzyme $\left(<0.01 \mathrm{ng} \mathrm{mL}^{-1}\right)$ after which point it steadily decreased till the end of the period remaining significantly higher.

$\mathrm{CKMB}$ blood concentrations $\left(\mathrm{UL}^{-1}\right)$ in control group and SCAD, ACS-UA, and ACS-STEMI patients during the eight-day period are shown in Figure 3. CKMB blood values remained within normal physiological range (between 0 and $25 \mathrm{U} \mathrm{L}^{-1}$ ) in control group as well as in SCAD and ACS-UA patients. On the other hand, CKMB blood concentrations in ACS-STEMI patients were significantly increased on the first and second day (see Figure 3). CKMB level in ACSSTEMI patients achieved a peak value in the first 24 hours of their acute events ( 4 times higher than physiological value for this cardiac specific enzyme), and after that point its level



FIGURE 3: CKMB blood concentration $\left(\mathrm{UL}^{-1}\right)$ in control group $(n=32)$, stable coronary artery disease patients (SCAD, $n=$ 28 ), acute coronary syndrome, nonocclusive type, patients (ACS$\mathrm{UA}, n=26$ ), and acute coronary syndrome, occlusive type, patients (ACS-STEMI, $n=37$ ) during the eight-day period of testing. CKMB blood concentrations in control, SCAD, and ACS-UA groups were in normal physiological range during the whole investigated period (between 0 and $25 \mathrm{UL}^{-1}$ ). The data are presented by means \pm SEM.

decreased and returned to its normal physiological range after the third day of analysis.

\section{Discussion}

For more than two decades histamine has been considered to be one of the vasoactive metabolites which are released in coronary circulation during myocardial ischemia. Clinically, increased blood histamine levels have been described in patients with ischemic heart diseases by Kounis and Zavras [23]. Furthermore, experimental studies have documented that coronary histamine mostly originates from cardiac mast cells [24] and activated platelets [25, 26].

Up to now the histamine blood levels in the patients suffering from ischemic heart diseases have been measured only in the first 24 hours of acute event [21]. However, there is a deficiency of data regarding histamine blood concentration in patients suffering from ischemic heart diseases for longer periods, which is why this study examines histamine blood concentration during the eight-day period in subjects suffering from different types of ischemic heart diseases.

In this study (Table 1), observed groups were uniform in terms of age, sex, smoking habits, and physical activity. Hypertension, heredity, and diabetes mellitus type II, as well as lipids in the blood were more frequent in patients with ischemic heart disease than in the control group. These data 
are in accordance with previous reports [27-31], reflecting relationship between mentioned risk factors and coronary endothelial dysfunction.

Statistically speaking, significantly higher levels of blood histamine are found in SCAD, ACS-UA, and ACS-STEMI patients compared with control group during the whole period (Figure 1).

SCAD patients showed significantly increased histamine blood concentration (up to $79.5 \pm 3.6 \mathrm{ng} \mathrm{mL}^{-1}$ ) compared with the control group $\left(44.87 \pm 1.09 \mathrm{ng} \mathrm{mL}^{-1}\right)$. Obtained values were lower than those in ACS-STEMI patients during the whole eight-day period, in comparison to ACS-UA patients where they were lower only during the first five days.

The process of atherosclerosis leads to lipids accumulation in the blood vessel wall, activating cardiac mast cells, which, in turn, cause an increase in coronary histamine concentration [6]. Furthermore, atherosclerosis leads to narrowing of epicardial coronary arteries, thus compromising the flow of coronary vascular bed, resulting in inadequate blood supply to the heart muscle (ischemia). Myocardial ischemia and consequent hypoxia also promote the degranulation of cardiac mast cells, leading to the release of histamine $[24,32]$. This can be the cause of significantly higher and sustained histamine blood concentration in SCAD patients compared with the control group. Our results demonstrate that the increased concentration of histamine in patients with stable form of coronary artery disease was not significantly different depending on the time of blood sampling during the eightday monitoring and remained at about $80 \mathrm{ng} \mathrm{mL}^{-1}$.

Figure 1 shows that ACS-UA patients had higher histamine blood concentration compared with the control group during the entire monitoring, and for the first five days these values were significantly higher than those in SCAD patients as well. On the sixth day the measured value was $81.1 \pm 1.2 \mathrm{ng} \mathrm{mL}^{-1}$, while on the seventh and eighth days the measured concentrations of histamine in ACS-UA patients were below $80 \mathrm{ng} \mathrm{mL}^{-1}$. These results suggest that ACS-UA patients have significantly higher blood histamine levels on the 1st admission day $\left(84.8 \pm 1.2 \mathrm{ng} \mathrm{mL}^{-1}\right)$ as well as within the next four days when compared to SCAD patients. Interestingly, the peak of histamine increase in the ACS-UA patients $\left(90.85 \pm 2.4 \mathrm{ng} \mathrm{mL}^{-1}\right)$ occurs on the second day indicating additional histamine release within the first 48 hours. In the last three days, none of the measured concentrations differed significantly from the blood histamine concentration of SCAD patients for the same period. This indicates stabilization and transition of unstable form of disease to a stable one.

Pathophysiological basis for unstable angina pectoris is unstable atherosclerosis plaque complicated with endothelial damage, activation of platelets and spasm (reversible ischemia) [33]. The role of histamine in the erosion or rupture of coronary plaque is not defined, but there are investigations that show that chronic activation of mast cells in the atherosclerotic lesions predisposes the subject to this event [6]. Further, the proportion of activated and degranulated adventitial mast cells was found to be the highest in the segments with ruptured plaques [32] leading to higher histamine release [6]. The damaged endothelium leads to activation and secretion of platelet which, in addition to ADP, coagulation factors, growth factors, and serotonin [34], secretes histamine too [20]. Furthermore, via H1 receptors histamine induces expression of tissue factor (TF), a key enzyme in the activation of coagulation [5]. The process of coagulation with the formation of a thrombus results in the narrowing of blood vessels, ischemia, and hypoxia which leads to further activation of mast cells and platelets, which then release new amounts of histamine [26, 35, 36]. All this indicates the reasons of significantly increased histamine concentration in our patients with unstable angina. Also, unstable angina is characterized by dynamic narrowing due to spasm of the coronary arteries in addition to the mechanical narrowing. Spasm, together with the process of coagulation, significantly increases ischemia leading to the histamine release from activated mast cells [26]. Further, Sakata et al. [37] observed that the coronary histamine is elevated shortly before coronary spasm, as discussed elsewhere [38], and Kounis and Zavras [23] suggest that chest pain in patients with unstable angina triggered by coronary spasm can be provoked by histamine. Thus a vicious circle is created: (1) erosion or rupture of unstable atherosclerotic plaque leads to mechanical constriction that causes the release of histamine, (2) released histamine increases coronary artery spasm, and (3) spasm exacerbates ischemia and hypoxia releasing new amounts of histamine. Perhaps the reason for several days of increased concentrations of histamine in our ACS-UA patients is the given mechanism. However, unstable angina is characterized by reversible ischemia, which was confirmed in our study by the negative values of cardiac enzymes. So the stabilization of plaque leads to better blood circulation and consequently less hypoxia, which could be the reason for significantly lower concentrations of histamine in our patients on the sixth, seventh, and eighth days of testing.

The blood levels of troponin I (Figure 2) as well as CKMB (Figure 3) were in normal physiological range in ACS-UA patients during the testing. This suggests that in our study histamine appears to be a more sensitive parameter for myocardial ischemia than the cardiac specific enzymes.

Of all the four groups, the highest increase of histamine blood concentration was measured in ACS-STEMI patients (Figure 1). Our results show that histamine blood concentration in ACS-STEMI patients achieved a peak value (121.7 $\pm 6.34 \mathrm{ng} \mathrm{mL}^{-1}$ ) on the second day of their acute events, after which point histamine blood level decreased to the end of the observed period steadily remaining significantly higher when compared with the corresponding histamine blood levels in the other groups. These data are in accordance with previous data that histamine blood concentration increases as the disease becomes more severe [6]. ACSSTEMI is the most serious form of unstable coronary disease characterized by irreversible ischemia and necrosis of myocardial tissue, caused by occlusion of blood vessel [33]. Cardiac troponins are the biomarkers of choice for detection of myocardial necrosis, and the determination of these enzymes is very useful for the measurement of the extent of necrosis [39-42]. Also, it is noted that histamine blood level has been dependent on the infarct size [32]. The increased number of adventitial mast cells was found 
to correlate with the progression of atherosclerosis, and their presence is particularly high in areas of arterial thrombosis [6]. Importantly, the highest numbers of intimal mast cells have been found at sites of rupture and/or erosion in infarctrelated coronary arteries [7]. We must not forget that in these patients thrombin and collagen stimulate platelets to release histamine as well $[25,43]$.

These data are in accordance with our results that ACS-STEMI patients have the highest histamine blood concentration compared with the other groups and its level remained above $80 \mathrm{ng} \mathrm{mL}^{-1}$ during the whole eight-day period (Figure 1). Acute coronary event with occlusion of coronary blood vessel causes severe injury to neighboring cells (mast cell necrosis) and leads to massive histamine release as illustrated by high histamine values in our patients. Furthermore, troponin I blood concentration as well as CKMB concentration in ACS-STEMI patients was significantly increased, and their values peaked in the first 24 hours (Figures 2 and 3). These data are in accordance with other reports [44], proving the correlation between myocardial cell injury and release of cardiac specific enzymes. Also, as in ACS-UA patients, in ACS-STEMI patients, additional histamine release has been detected within 48 hours after admission. This peak of histamine concentration on the second day was even more pronounced when compared with ACS-UA patients. The additional histamine release on the second day in ACS-UA and ACS-STEMI patients was not detected in SCAD patients which can be explained as the consequence of the reperfusion after previous ischemia. The fact that histamine is released in ischemia-reperfusion conditions is well known $[45,46]$.

Previous studies have shown that half-life of plasma histamine and plasma troponin I measures in minutes and days, respectively $[47,48]$. Because of troponin long halflife, it is not useful for detection of early reinfarction, which is why the rise of histamine blood concentration may be a parameter for detection of such events.

Finally, it is well known that smoking habit is also a risk factor for atherosclerosis, and nicotine present in smoke extract has been shown to activate human mast cells $[6,49]$ and histamine release. However, in our study, the groups did not differ in smoking habits (Table 1). It is important to underline the fact that there were no statistically significant differences in histamine blood concentration between patients in the same group according to smoking habits $(P>.05)$. That means that mast cell activation provoked by smoking did not significantly influence histamine release in our study. Furthermore, in our study there were no statistically significant differences in histamine blood concentration among subjects in control group according to the incidence of hypertension, type II diabetes, or dyslipidemias, and there are no known data published indicating that such diseases may have impact on histamine blood concentration.

\section{Conclusions}

In this study we investigated histamine blood concentration in subjects suffering from different types of ischemic heart diseases (stable coronary artery disease, acute coronary syndrome, nonocclusive type, and acute coronary syndrome, occlusive type) during the eight-day testing period.

We found evidence that the histamine blood level is associated with different types of ischemic heart disease.

The histamine level in blood in all research subjects was significantly higher when compared to control subjects, indicating the increase of histamine release in the patients suffering from coronary diseases. In the patients suffering from ACS-UA and ACS-STEMI, the second day peak of histamine level occurs probably as the reperfusion event.

Furthermore, our data suggest that histamine can be additional parameter of myocardial ischemia along with cardiac specific enzymes such as troponin I and CKMB and may prove to be an excellent single prognostic marker for multitude of ischemic heart diseases.

\section{References}

[1] K. L. Morse, J. Behan, T. M. Laz et al., "Cloning and characterization of a novel human histamine receptor," Journal of Pharmacology and Experimental Therapeutics, vol. 296, no. 3, pp. 1058-1066, 2001.

[2] A. A. Wolff and R. Levi, "Histamine and cardiac arrhythmias," Circulation Research, vol. 58, no. 1, pp. 1-16, 1986.

[3] M. A. Beaven, "Our perception of the mast cell from Paul Ehrlich to now," European Journal of Immunology, vol. 39, no. 1, pp. 11-25, 2009.

[4] M. Huang, X. Pang, R. Letourneau, W. Boucher, and T. C. Theoharides, "Acute stress induces cardiac mast cell activation and histamine release, effects that are increased in Apolipoprotein E knockout mice," Cardiovascular Research, vol. 55, no. 1, pp. 150-160, 2002.

[5] J. Steffel, M. Hermann, H. Greutert et al., "Celecoxib decreases endothelial tissue factor expression through inhibition of cJun terminal NH2 kinase phosphorylation," Circulation, vol. 111, no. 13, pp. 1685-1689, 2005.

[6] K. A. Lindstedt, M. I. Mäyränpää, and P. T. Kovanen, "Mast cells in vulnerable atherosclerotic plaques - a view to a kill," Journal of Cellular and Molecular Medicine, vol. 11, no. 4, pp. 739-758, 2007.

[7] P. T. Kovanen, M. Kaartinen, and T. Paavonen, "Infiltrates of activated mast cells at the site of coronary atheromatous erosion or rupture in myocardial infarction," Circulation, vol. 92, no. 5, pp. 1084-1088, 1995.

[8] H. Li, C. Burkhardt, U. R. Heinrich, I. Brausch, N. Xia, and U. Förstermann, "Histamine upregulates gene expression of endothelial nitric oxide synthase in human vascular endothelial cells," Circulation, vol. 107, no. 18, pp. 2348-2354, 2003.

[9] W. Liao, M. Rudling, and B. Angelin, "Novel effects of histamine on lipoprotein metabolism: suppression of hepatic low density lipoprotein receptor expression and reduction of plasma high density lipoprotein cholesterol in the rat," Endocrinology, vol. 138, no. 5, pp. 1863-1870, 1997.

[10] J. Van der Voorde, V. Brochez, and B. Vanheel, "Heterogenous effects of histamine on isolated rat coronary arteries," European Journal of Pharmacology, vol. 271, no. 1, pp. 17-23, 1994.

[11] T. Nakane and S. Chiba, "Characteristics of histamine receptors in the isolated and perfused canine coronary arteries," Archives Internationales de Pharmacodynamie et de Therapie, vol. 290, no. 1, pp. 92-103, 1988. 
[12] N. Toda, "Mechanism of histamine actions in human coronary arteries," Circulation Research, vol. 61, no. 2, pp. 280-286, 1987.

[13] F. Lantoine, L. Iouzalen, M. A. Devynck, E. Millanvoye-Van Brussel, and M. David-Dufilho, "Nitric oxide production in human endothelial cells stimulated by histamine requires $\mathrm{Ca}^{2+}$ influx," Biochemical Journal, vol. 330, no. 2, pp. 695-699, 1998.

[14] H. Li, C. Burkhardt, U. R. Heinrich, I. Brausch, N. Xia, and U. Förstermann, "Histamine upregulates gene expression of endothelial nitric oxide synthase in human vascular endothelial cells," Circulation, vol. 107, no. 18, pp. 2348-2354, 2003.

[15] M. Singh and H. K. Saini, "Resident cardiac mast cells and ischemia-reperfusion injury," Journal of Cardiovascular Pharmacology and Therapeutics, vol. 8, no. 2, pp. 135-148, 2003.

[16] S. Bertuglia and A. Giusti, "Microvascular oxygenation, oxidative stress, NO suppression and superoxide dismutase during postischemic reperfusion," American Journal of Physiology, vol. 285, no. 3, pp. H1064-H1071, 2003.

[17] A. V. Gourine, A. T. Gonon, and J. Pernow, "Involvement of nitric oxide in cardioprotective effect of endothelin receptor antagonist during ischemia-reperfusion," American Journal of Physiology, vol. 280, no. 3, pp. H1105-H1112, 2001.

[18] X. S. Li, Y. Uriuda, Q. D. Wang, R. Nordlander, P. O. Sjöquist, and J. Pernow, "Role of L-arginine in preventing myocardial and endothelial injury following ischaemia/reperfusion in the rat isolated heart," Acta Physiologica Scandinavica, vol. 156, no. 1, pp. 37-44, 1996.

[19] S. Pierpaoli, C. Marzocca, M. G. Bello, W. Schunack, P. F. Mannaioni, and E. Masini, "Histaminergic receptors modulate the coronary vascular response in isolated guinea pig hearts. Role of nitric oxide," Inflammation Research, vol. 52, no. 9, pp. 390-396, 2003.

[20] P. F. Mannaioni, M. G. Di Bello, and E. Masini, "Platelets and inflammation: role of platelet-derived growth factor, adhesion molecules and histamine," Inflammation Research, vol. 46, no. 1, pp. 4-18, 1997.

[21] S. Clejan, S. Japa, C. Clemetson, S. S. Hasabnis, O. David, and J. V. Talano, "Blood histamine is associated with coronary artery disease, cardiac events and severity of inflammation and atherosclerosis," Journal of Cellular and Molecular Medicine, vol. 6, no. 4, pp. 583-592, 2002.

[22] P. A. Shore, A. Burkhalter, and V. H. Cohn Jr., "A method for the fluorometric assay of histamine in tissues," The Journal of Pharmacology and Experimental Therapeutics, vol. 127, no. 3, pp. 182-186, 1959.

[23] N. G. Kounis and G. M. Zavras, "Histamine-induced coronary artery spasm: the concept of allergic angina," British Journal of Clinical Practice, vol. 45, no. 2, pp. 121-128, 1991.

[24] N. G. Frangogiannis, M. L. Lindsey, L. H. Michael et al., "Resident cardiac mast cells degranulate and release preformed TNF- $\alpha$, initiating the cytokine cascade in experimental canine myocardial ischemia/reperfusion," Circulation, vol. 98, no. 7, pp. 699-710, 1998.

[25] E. Masini, M. G. Di Bello, S. Raspanti et al., "The role of histamine in platelet aggregation by physiological and immunological stimuli," Inflammation Research, vol. 47, no. 5, pp. 211-220, 1998.

[26] K. Nakahodo, S. Saitoh, M. Nakamura, and T. Kosugi, "Histamine release from rabbit platelets by platelet-activating factor (PAF)," Japanese Journal of Allergology, vol. 43, no. 3, pp. 501-510, 1994.
[27] J. Gofman, H. Jones, F. Lindgreen, T. Lyon, Elliott H., and B. Strisower, "Blood lipids and human atherosclerosis," Circulation, vol. 2, no. 2, pp. 161-178, 1950.

[28] M. A. Ford, J. P. McConnell, S. Lavi et al., "Coronary artery endothelial dysfunction is positively correlated with low density lipoprotein and inversely correlated with high density lipoprotein subclass particles measured by nuclear magnetic resonance spectroscopy," Atherosclerosis, vol. 207, no. 1, pp. $111-115,2009$.

[29] R. W. Nesto, "Beyond low-density lipoprotein: addressing the atherogenic lipid triad in type 2 diabetes mellitus and the metabolic syndrome," American Journal of Cardiovascular Drugs, vol. 5, no. 6, pp. 379-387, 2005.

[30] K. S. Stamatelopoulos, G. D. Kitas, C. M. Papamichael et al., "Atherosclerosis in rheumatoid arthritis versus diabetes: a comparative study," Arteriosclerosis, Thrombosis, and Vascular Biology, vol. 29, no. 10, pp. 1702-1708, 2009.

[31] S. Makita, H. Matsui, Y. Naganuma, A. Abiko, M. Tamada, and M. Nakamura, "Diabetic state as a crucial factor for impaired arterial elastic properties in patients with peripheral arterial disease," Atherosclerosis, vol. 208, no. 1, pp. 167-170, 2010.

[32] P. Laine, M. Kaartinen, A. Penttilä, P. Panula, T. Paavonen, and P. T. Kovanen, "Association between myocardial infarction and the mast cells in the adventitia of the infarct-related coronary artery," Circulation, vol. 99, no. 3, pp. 361-369, 1999.

[33] V. Fuster, L. Badimon, J. J. Badimon, and J. H. Chesebro, “The pathogenesis of coronary artery disease and the acute coronary syndromes (1)," New England Journal of Medicine, vol. 326, no. 4, pp. 242-250, 1991.

[34] K. K. Wu, "Platelet activation mechanisms and markers in arterial thrombosis," Journal of Internal Medicine, vol. 239, no. 1, pp. 17-34, 1996.

[35] N. A. Flores, N. V. Goulielmos, M. J. Seghatchian, and D. J. Sheridan, "Myocardial ischaemia induces platelet activation with adverse electrophysiological and arrhythmogenic effects," Cardiovascular Research, vol. 28, no. 11, pp. 1662-1671, 1994.

[36] L. W. Fu and J. C. Longhurst, "Activated platelets contribute to stimulation of cardiac afferents during ischaemia in cats: role of 5-HT3 receptors," Journal of Physiology, vol. 544, no. 3, pp. 897-912, 2002.

[37] Y. Sakata, K. Komamura, A. Hirayama et al., "Elevation of the plasma histamine concentration in the coronary circulation in patients with variant angina," American Journal of Cardiology, vol. 77, no. 12, pp. 1121-1125, 1996.

[38] R. Ginsburg, M. R. Bristow, and N. Kantrowitz, "Histamine provocation of clinical coronary artery spasm: implications concerning pathogenesis of variant angina pectoris," American Heart Journal, vol. 102, no. 5, pp. 819-822, 1981.

[39] E. M. Antman, M. J. Tanasijevic, B. Thompson et al., "Cardiacspecific troponin I levels to predict the risk of mortality in patients with acute coronary syndromes," New England Journal of Medicine, vol. 335, no. 18, pp. 1342-1349, 1996.

[40] T. Keller, T. Zeller, D. Peetz et al., "Sensitive troponin I assay in early diagnosis of acute myocardial infarction," New England Journal of Medicine, vol. 361, no. 9, pp. 868-877, 2009.

[41] T. Reichlin, W. Hochholzer, S. Bassetti et al., "Early diagnosis of myocardial infarction with sensitive cardiac troponin assays," New England Journal of Medicine, vol. 361, no. 9, pp. 858-867, 2009.

[42] P. A. Kavsak, X. Wang, D. T. Ko, A. R. MacRae, and A. S. Jaffe, "Short- and long-term risk stratification using a next-generation, high-sensitivity research cardiac troponin 
I (hs-cTnI) assay in an emergency department chest pain population," Clinical Chemistry, vol. 55, no. 10, pp. 1809$1815,2009$.

[43] L. W. Fu, W. Schunack, and J. C. Longhurst, "Histamine contributes to ischemia-related activation of cardiac spinal afferents: role of $\mathrm{H}_{1}$ receptors and PKC," Journal of Neurophysiology, vol. 93, no. 2, pp. 713-722, 2005.

[44] A. Chiu, W. K. Chan, S. H. Cheng, C. K. Leung, and C. H. Choi, "Troponin-I, myoglobin, and mass concentration of creatine kinase-MB in acute myocardial infarction," QJM Monthly Journal of the Association of Physicians, vol. 92, no. 12, pp. 711-718, 1999.

[45] H. Asanuma, T. Minamino, A. Ogai et al., "Blokade of histamine $\mathrm{H}_{2}$ receptors protects the heart against ischemia and reperfusion injury in dogs," Journal of Molecular \& Cellular Cardiology, vol. 40, no. 5, pp. 666-674, 2006.

[46] M. Rosic, S. Pantovic, G. Rosic et al., "Glucagon effects on ischemic vasodilatation in the isolated rat heart," Journal of Biomedicine and Biotechnology, vol. 2010, Article ID 231832, 7 pages, 2010.

[47] D. Laroche, F. Dubois, J. L. Gerard et al., "Radioimmunoassay for plasma histamine: a study of false positive and false negative values," British Journal of Anaesthesia, vol. 74, no. 4, pp. 430-437, 1995.

[48] K. Ellis, A. W. Dreisbach, and J. J. L. Lertora, "Plasma elimination of cardiac troponin I in end-stage renal disease," Southern Medical Journal, vol. 94, no. 10, pp. 993-996, 2001.

[49] A. Small-Howard and H. Turner, "Exposure to tobaccoderived materials induces overproduction of secreted proteinases in mast cells," Toxicology and Applied Pharmacology, vol. 204, no. 2, pp. 152-163, 2005. 


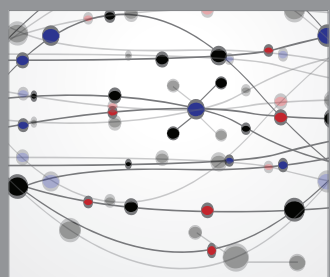

The Scientific World Journal
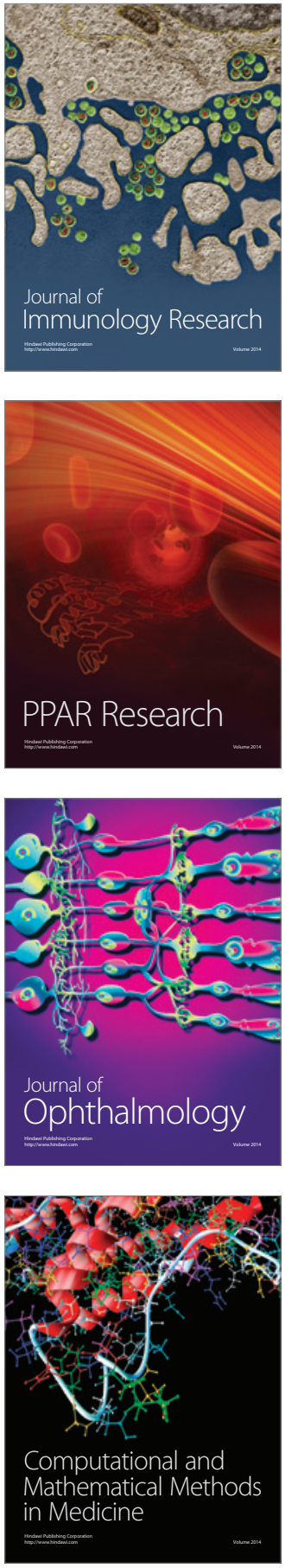



Gastroenterology

Research and Practice
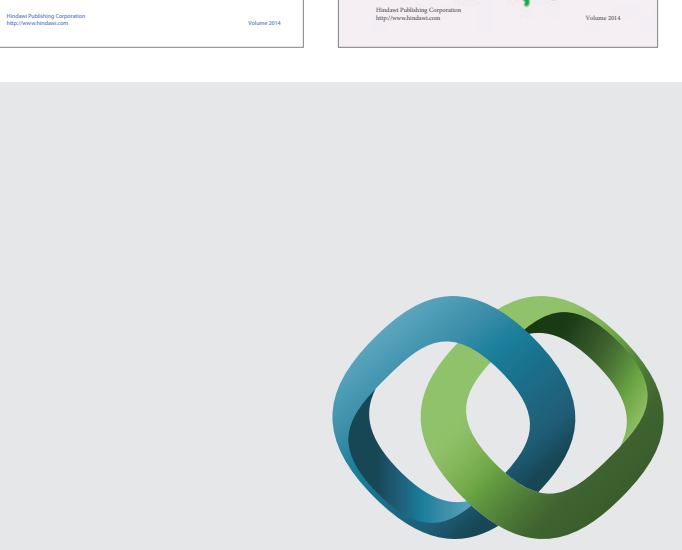

\section{Hindawi}

Submit your manuscripts at

http://www.hindawi.com


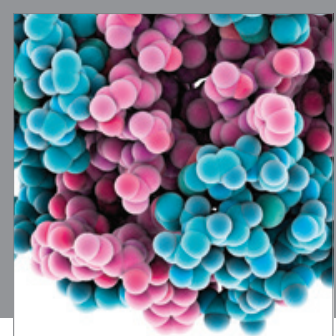

Journal of
Diabetes Research

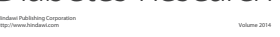

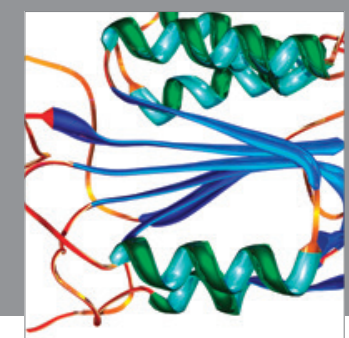

Disease Markers
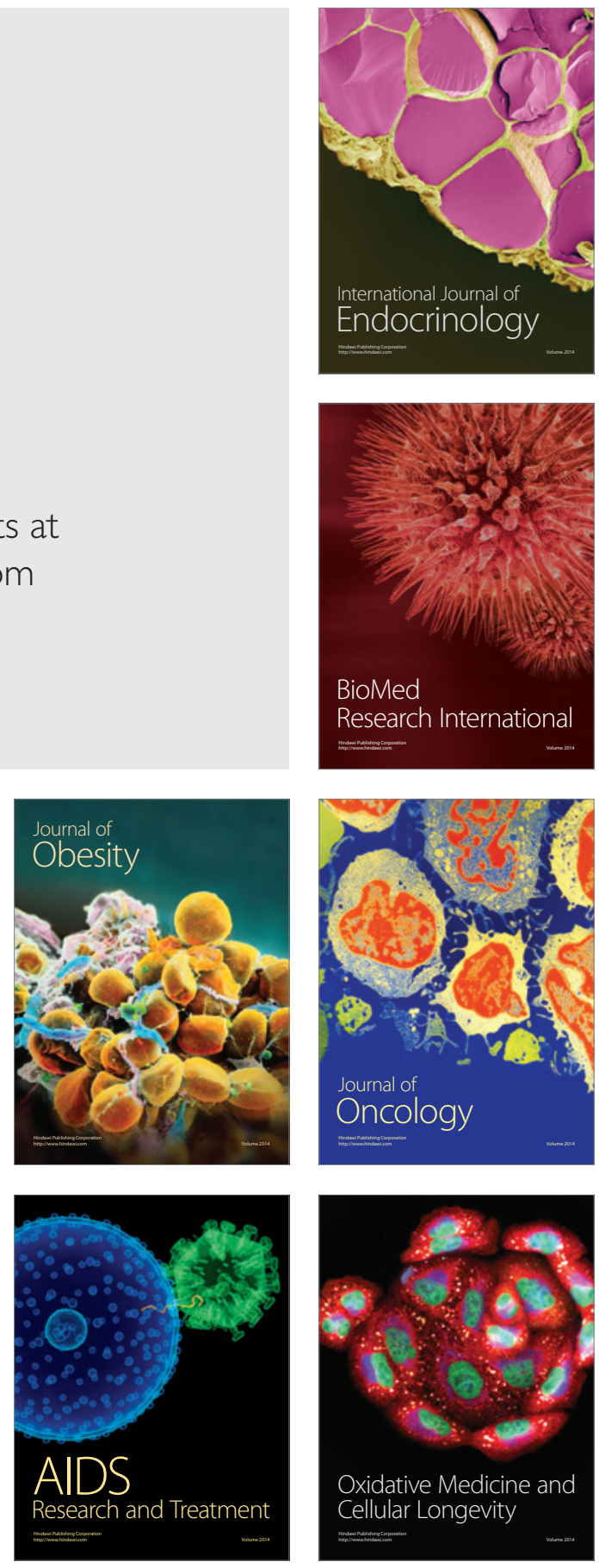